\title{
Effect of Criteria Range on the Similarity of Results in the COMET Method
}

\author{
Andrii Shekhovtsov, Jakub Więckowski, Bartłomiej Kizielewicz and Wojciech Sałabun \\ Research Team on Intelligent Decision Support Systems, \\ Department of Artificial Intelligence Methods and Applied Mathematics, \\ Faculty of Computer Science and Information Technology \\ West Pomeranian University of Technology in Szczecin \\ ul. Żołnierska 49, 71-210 Szczecin, Poland \\ Email: \{andrii-shekhovtsov, jakub-wieckowski, bartlomiej-kizielewicz,wojciech.salabun\}@zut.edu.pl
}

\begin{abstract}
Defining input values in the decision-making process can be done with appropriate methods or based on expert knowledge. It is essential to ensure that the values are adequate for the problem to be solved in both cases. There may be situations where values are overestimated, and it should be checked whether this affects the final results.

In this paper, the Characteristic Objects Method (COMET) was used to investigate the overestimation effect on the final rankings. The decision matrixes with a different number of alternatives and criteria were assessed The obtained results were compared using the WS similarity coefficient and Spearman's weighted correlation coefficient. The study showed that overestimation has a significant effect on the rankings. A larger number of criteria has a positive effect on the correlation strength of the compared rankings. In contrast, a large overestimation of characteristic values has a negative effect on the similarity of the results.
\end{abstract}

\section{INTRODUCTION}

In decision-making, expert knowledge is an important element influencing the results obtained [1]. It is important in specifying the importance of criteria and the weighting of each criterion in the process of evaluating alternatives [2], [3]. These decisions directly translate into the obtained preference values guaranteed by the selected multi-criteria methods [4], [5], [6].

For some Multi-Criteria Decision-Making (MCDM) methods to solve decision-making problems, the expert must define the algorithm's input parameters based on his experience and knowledge [7], [8]. Some methods allow the use of methods that determine weights for criteria in a defined problem [9], [10]. In other cases, the data determined for the method's operation must be specified solely based on expert knowledge [11], [12]. Multi-Criteria Decision-Making methods are eagerly used in solving problems where many factors contribute to the final assessment [13]. The development of new techniques attracts the attention of a growing audience, who use them to solve medical problems [14], [15], [16], [17], for resource planning [18], [19], [20], or the selection of sustainable means of transport [21], [22], [23].

One of the multi-criteria methods is the Characteristic Objects Method (COMET), which uses the rule-based approach when evaluating the quality of alternatives [24]. The expert's task using this method to solve the problem is to determine the characteristic values, which will be used to assess the preference of alternatives in subsequent steps [25], [26]. The advantage of this method is that it is resistant to the phenomenon of ranking reversal when the number of alternatives in the analyzed set changes [8].

In this paper, based on the COMET method's operation, an attempt has been made to determine the effect of overestimation of characteristic values on the results depending on the number of alternatives and criteria. Different levels of overestimation were used to examine and compare the results obtained. The results were then compared using the WS similarity coefficient and the weighted Spearman correlation coefficient to analyze the resulting rankings' correlation.

The rest of the paper is organized as follows. Section 2 presents the preliminaries and main assumptions of the COMET method. Section 3 includes the study case description, where the influence of the overestimation of characteristic values on the received results was examined. Finally, in Section 4 the summary and conclusions from the research are drawn.

\section{PRELIMINARIES}

\section{A. Weighted Spearman's Rank Coefficient}

Weighted Spearman's rank coefficient is defined as (1), where $N$ is a sample size, rank values for both rankings is named as $x_{i}$ and $y_{i}$. In this approach, the positions at the top of both rankings are the most important. The weight of significance is calculated for each alternative. It is the element that determines the main difference to Spearman's rank correlation coefficient, which examines whether the differences appeared and not where they appeared [27].

$$
r_{w}=1-\frac{6 \sum_{i=1}^{N}\left(x_{i}-y_{i}\right)^{2}\left(\left(N-x_{i}+1\right)+\left(N-y_{i}+1\right)\right)}{N^{4}+N^{3}-N^{2}-N}
$$

\section{B. WS Rank Similarity Coefficient}

Rank Similarity Coefficient $W S$ is defined as (2). Unlike $r_{w}$, it is an asymmetric measure. The weight of a given comparison is determined based on the significance of the 


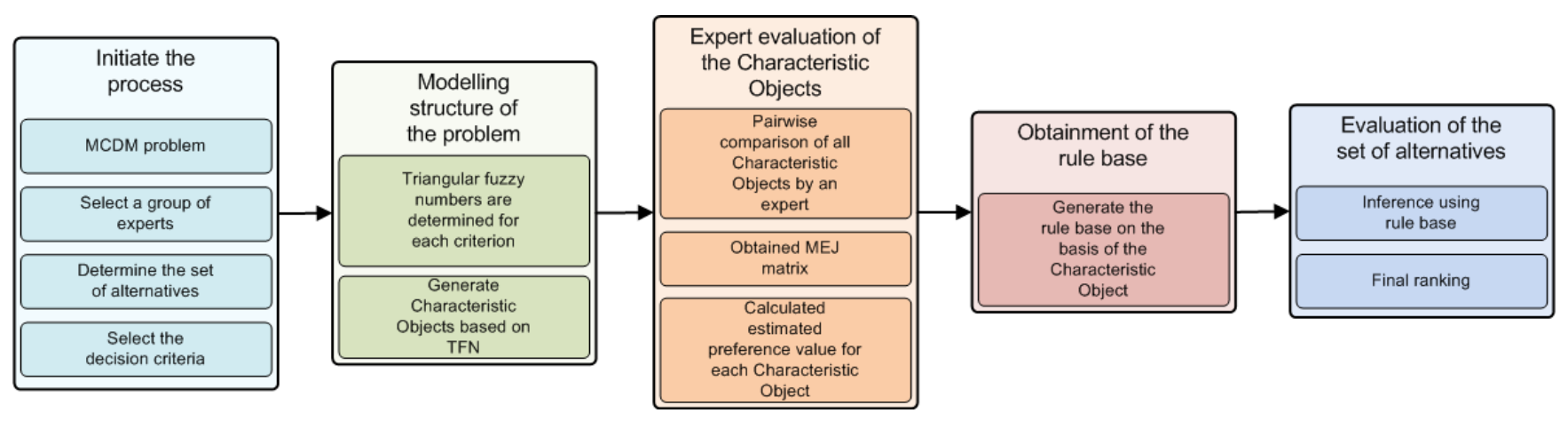

Fig. 1. The detailed procedure of the characteristic objects method (COMET).

position in the first ranking, which is used as a reference ranking [28].

$$
W S=1-\sum_{i=1}^{N} 2^{-x_{i}} \frac{\left|x_{i}-y_{i}\right|}{\max \left(\left|x_{i}-1\right|,\left|x_{i}-N\right|\right)}
$$

\section{The Characteristic Objects Method}

The Characteristic Objects Method (COMET) is the first method which is completely free of the rank reversal phenomenon [29]. The preferences for the set of alternatives are calculated using the rule base, which is obtained in the process of the pairwise comparison for the Characteristic Objects (COs) [30], [31], [32]. The main assumptions of the COMET method are shortly recalled below following [33]. Additionally, Fig. 1 presents the whole flowchart of the COMET procedure.

Step 1. Define the space of the problem.

An expert determines dimensionality of the problem by selecting number $r$ of criteria, $C_{1}, C_{2}, \ldots, C_{r}$. Subsequently, the set of fuzzy numbers for each criterion $C_{i}$ is selected, i.e., $\tilde{C}_{i 1}, \tilde{C}_{i 2}, \ldots, \tilde{C}_{i c_{i}}$. Each fuzzy number determines the value of the membership for a particular linguistic concept for specific crisp values. Therefore it is also useful for variables that are not continuous. In this way, the following result is obtained (3).

$$
\begin{aligned}
& C_{1}=\left\{\tilde{C}_{11}, \tilde{C}_{12}, \ldots, \tilde{C}_{1 c_{1}}\right\} \\
& C_{2}=\left\{\tilde{C}_{21}, \tilde{C}_{22}, \ldots, \tilde{C}_{2 c_{2}}\right\} \\
& C_{r}=\left\{\tilde{C}_{r 1}, \tilde{C}_{r 2}, \ldots, \tilde{C}_{r c_{r}}\right\}
\end{aligned}
$$

where $c_{1}, c_{2}, \ldots, c_{r}$ are numbers of the fuzzy numbers for all criteria.

Step 2. Generate the characteristic objects.

Characteristic objects are objects that define reference points in n-dimensional space. They can be either real or idealized objects that cannot exist [34], [35], [36]. The characteristic objects $(C O)$ are obtained by using the Cartesian product of fuzzy numbers cores for each criterion.
As the result, the ordered set of all $C O$ is obtained (4):

$$
\begin{aligned}
& C O_{1}=\left\{C\left(\tilde{C}_{11}\right), C\left(\tilde{C}_{21}\right), \ldots, C\left(\tilde{C}_{r 1}\right)\right\} \\
& C O_{2}=\left\{C\left(\tilde{C}_{11}\right), C\left(\tilde{C}_{21}\right), \ldots, C\left(\tilde{C}_{r 2}\right)\right\} \\
& \ldots \ldots \ldots \ldots \ldots \ldots \ldots \ldots \ldots \ldots \ldots \ldots \ldots \ldots \ldots \ldots \ldots \ldots \ldots \ldots \ldots \ldots \ldots \ldots \ldots \ldots \ldots \ldots \ldots \ldots \ldots \ldots \ldots \ldots \ldots \ldots \ldots \ldots \ldots \ldots \ldots \ldots \\
& C O_{t}=\left\{C\left(\tilde{C}_{1 c_{1}}\right), C\left(\tilde{C}_{2 c_{2}}\right), \ldots, C\left(\tilde{C}_{r c_{r}}\right)\right\}
\end{aligned}
$$

where $t$ is a number of $C O(5)$ :

$$
t=\prod_{i=1}^{r} c_{i}
$$

Step 3. Rank the characteristic objects.

The expert determines the Matrix of Expert Judgement $(M E J)$. It is a result of pairwise comparison of the characteristic objects according to the expert knowledge. The $M E J$ structure is as follows (6):

$$
M E J=\left(\begin{array}{cccc}
\alpha_{11} & \alpha_{12} & \ldots & \alpha_{1 t} \\
\alpha_{21} & \alpha_{22} & \ldots & \alpha_{2 t} \\
\ldots & \ldots & \ldots & \ldots \\
\alpha_{t 1} & \alpha_{t 2} & \ldots & \alpha_{t t}
\end{array}\right)
$$

where $\alpha_{i j}$ is a result of comparing $C O_{i}$ and $C O_{j}$ by the expert [37], [38]. The more preferred characteristic object gets one point and the second object get zero points. If the preferences are balanced, the both objects get half point. It depends solely on the knowledge of the expert and can be presented as (7):

$$
\alpha_{i j}= \begin{cases}0.0, & f_{\text {exp }}\left(C O_{i}\right)<f_{\text {exp }}\left(C O_{j}\right) \\ 0.5, & f_{\text {exp }}\left(C O_{i}\right)=f_{\text {exp }}\left(C O_{j}\right) \\ 1.0, & f_{\text {exp }}\left(C O_{i}\right)>f_{\text {exp }}\left(C O_{j}\right)\end{cases}
$$

where $f_{\text {exp }}$ is an expert mental judgement function. Afterwards, the vertical vector of the Summed Judgements $(S J)$ is obtained as follows (8):

$$
S J_{i}=\sum_{j=1}^{t} \alpha_{i j}
$$

The number of query is equal to $p=\frac{t(t-1)}{2}$ because for each element $\alpha_{i j}$ we can observe that $\alpha_{j i}=1-\alpha_{i j}$. In the last step, an approximate value of preference $P_{i}$ is assigned to each characteristic object using Algorithm 1. As a result, vector $P$ is obtained, where $i$-th row contains the approximate value of preference for $\mathrm{CO}_{i}$. 


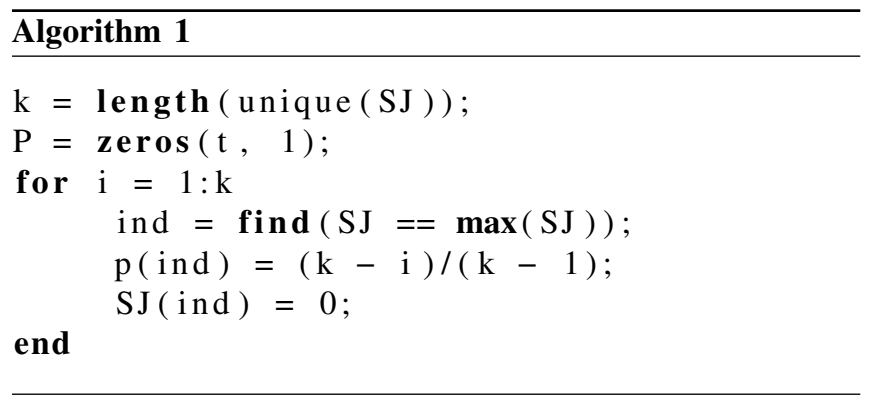

Step 4. The rule base.

Each characteristic object is converted into a fuzzy rule, where the degree of belonging to particular criteria is a premise for activating conclusions in the form of $P_{i}$. Each characteristic object and value of preference is converted to a fuzzy rule (for more details see [39]). $\mathrm{n}$ this way, the complete fuzzy rule base that approximates the expert mental judgement function $f_{\text {exp }}\left(C O_{i}\right)$ is obtained.

Step 5. Inference and final ranking.

The each one alternative $A_{i}$ is a set of crisp numbers $a_{r i}$ corresponding to criteria $C_{1}, C_{2}, \ldots, C_{r}$. It can be presented as follows (9):

$$
A_{i}=\left\{a_{1 i}, a_{2 i}, \ldots, a_{r i}\right\}
$$

Each alternative activates the specified number of fuzzy rules, where for each one the fulfilment degree of the complex conjunctive premise is determined. Fulfilment degrees of all activated rules are summed up to one. The preference of alternative is computed as the sum of products of all activated rules, their fulfilment degrees, and their values of the preference. The final ranking of alternatives is obtained by sorting the preference of alternatives, where one is the best result, and zero is the worst. More details can be found in [40], [41].

\section{CASE STUdy}

To determine the impact of overestimating the characteristic values in the application of the COMET method, it was decided to carry out two research cases, in which changes in the obtained rankings were observed. In the first case study different numbers of alternatives $([5,10,15,20,30])$ were taken into account, with the number of criteria equal to 4 . The second case study involved changes in the number of criteria $([4,6,8])$, with 10 alternatives in the considered set.

Additionally, in both research cases, the types of criteria were determined by dividing the number of criteria in half and assigning the profit type to one of them and the cost type to the other. Moreover, the established levels of overestimation of characteristic values were described by the range $[0.05$, $0.10,0.15,0.20,0.25,0.30]$. It is also worth mentioning that the Characteristic Objects values were defined as $[0,0.5,1]$. The overestimation level was subtracted and added for the lower and upper limits of the COs, respectively. The obtained alternatives' preference rankings were then compared using the WS similarity coefficient and the weighted Spearman correlation coefficient.

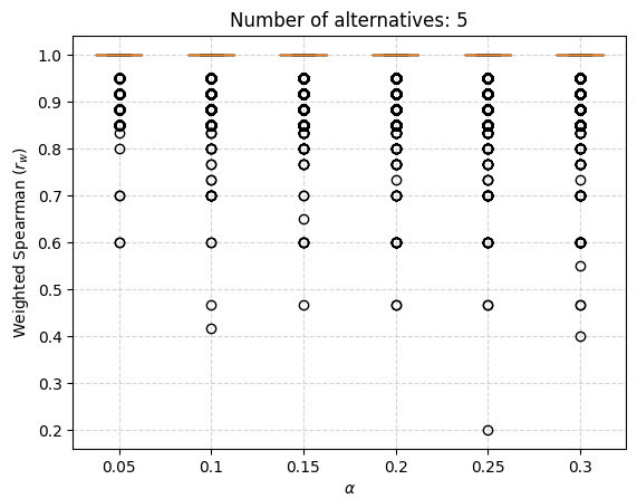

Fig. 2. Distribution of $r_{w}$ similarity coefficient for rankings with five alternatives and four criteria.

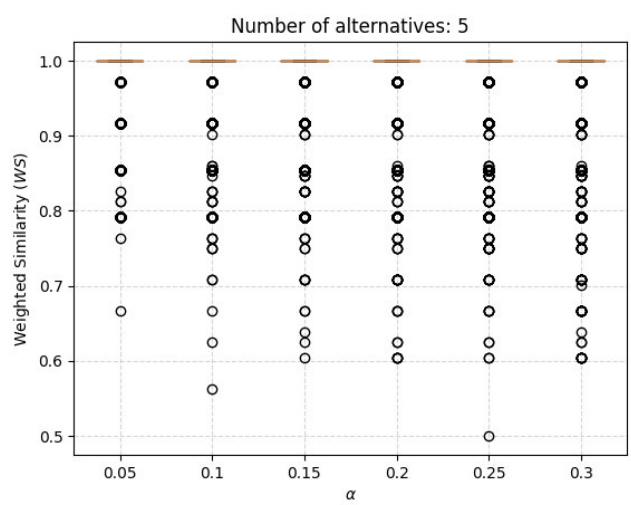

Fig. 3. Distribution of $W S$ similarity coefficient for rankings with five alternatives and four criteria.

Fig. 2 and 3 present a visualization of the ranking values obtained for a matrix size of 5 alternatives and 4 criteria for both similarity coefficients. In both cases, it can be seen that the least divergent values were obtained in the case when the overestimation level was 0.05 . In the WS coefficient case, the correlation values were less differentiated. They mainly oscillated in the range $[0.6,1.0]$, while for the Spearman coefficient, the values were more diverse, where the interval settled in the range $[0.2,1.0]$. It can also be noted that the change in the overestimation of values in the examined interval $[0.15,0.30]$ did not significantly affect the differences between the rankings.

A test case with 15 alternatives and 4 criteria in the decision matrix showed that when the overestimation value was increased, the rankings' similarity decreased slightly for both similarity coefficients used. The values of the weighted Spearman coefficient returned higher similarity than the WS similarity coefficient. In the cases analyzed for the different overestimation values, the rankings showed a high similarity of above 0.92 for the Spearman coefficient and above 0.825 for the WS coefficient. The visualization is shown in Fig. 4 and 5 .

In turn, Fig. 6 and 7 show the correlation values obtained 


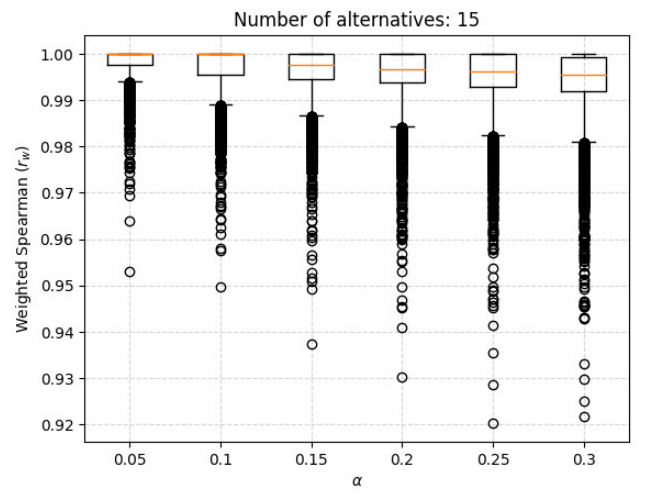

Fig. 4. Distribution of $r_{w}$ similarity coefficient for rankings with fifteen alternatives and four criteria.

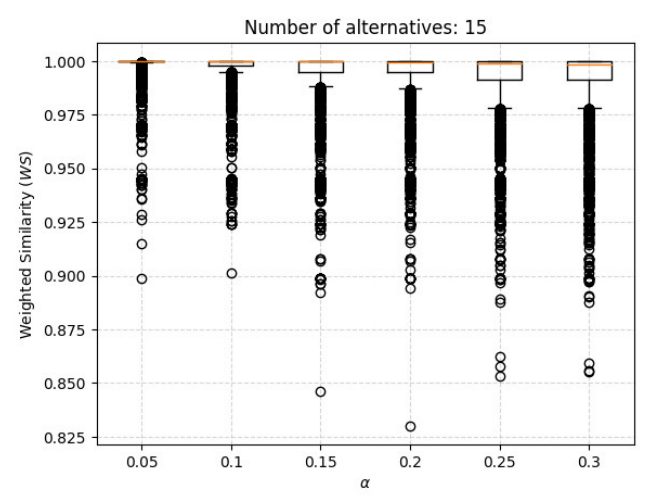

Fig. 5. Distribution of $W S$ similarity coefficient for rankings with fifteen alternatives and four criteria.

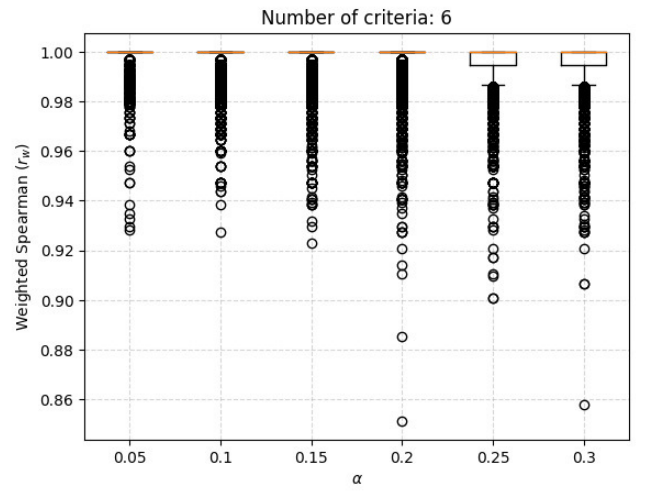

Fig. 6. Distribution of $r_{w}$ coefficient for rankings with ten alternatives and six criteria.

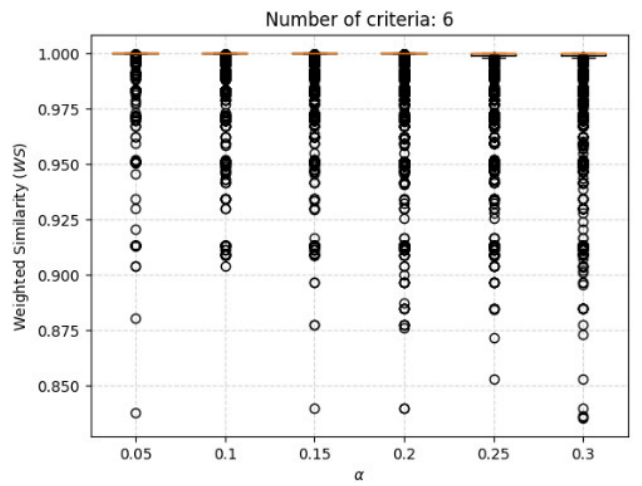

Fig. 7. Distribution of $W S$ similarity coefficient for rankings with ten alternatives and six criteria.

for the defined range of overestimation values and the decision matrix for 10 alternatives and 6 criteria. The returned correlations were similar and guaranteed values in the range $[0.85,1.0]$. It is worth noting that increasing the overestimation value again affected obtaining more significant variation in the rankings' similarity.

More significant overestimation had a negative effect on the obtained rankings correlation values and resulted in greater diversity. Additionally, it was noted that an increase in the number of criteria has a positive impact on the recorded similarity of the rankings.

\section{CONCLUSIONS}

Determining the impact of decisions made by the expert when using multi-criteria methods is an important element in the process of evaluating alternatives. The data defined by the expert, based on his knowledge and experience, can sometimes be overestimated, and it can directly impact the results achieved.

For this purpose, it was decided to use the COMET method, in which a numerical interval containing three values must be specified to define the Characteristic Objects. Values that change the baseline boundary limits were defined, which allowed the study of overestimating the final rankings. Two test cases were conducted in which changes in the number of alternatives with a constant number of criteria and changes in the number of criteria with a constant number of alternatives were investigated. The resulting rankings were then compared using two selected similarity coefficients. It was observed that a higher number of alternatives positively affects the correlation strength of the rankings. On the other hand, increasing the overestimation of the boundary values decreases the obtained results' similarity.

For further directions, it is worth considering how the overestimation affects the results when fuzzy extensions are involved in the COMET method application. Moreover, it can be determined whether the overestimation occurring in other MCDM methods can affect the resulting rankings. 


\section{ACKNOWLEDGMENT}

The work was supported by the National Science Centre, Decision number UMO-2018/29/B/HS4/02725 (W.S.).

\section{REFERENCES}

[1] J. J. Jassbi, R. A. Ribeiro, and L. R. Varela, "Dynamic mcdm with future knowledge for supplier selection," Journal of Decision Systems, vol. 23, no. 3, pp. 232-248, 2014.

[2] I. Vinogradova, V. Podvezko, and E. K. Zavadskas, "The recalculation of the weights of criteria in mcdm methods using the bayes approach," Symmetry, vol. 10, no. 6, p. 205, 2018.

[3] D. S. Pamučar, D. Božanić, and A. Ranđelović, "Multi-criteria decision making: An example of sensitivity analysis," Serbian journal of management, vol. 12, no. 1, pp. 1-27, 2017.

[4] S. Opricovic and G.-H. Tzeng, "Compromise solution by mcdm methods: A comparative analysis of vikor and topsis," European journal of operational research, vol. 156, no. 2, pp. 445-455, 2004.

[5] L. Ustinovichius, E. Zavadkas, and V. Podvezko, "Application of a quantitative multiple criteria decision making (mcdm-1) approach to the analysis of investments in construction," Control and cybernetics, vol. 36 , no. 1 , p. $251,2007$.

[6] B. Kizielewicz, J. Więckowski, A. Shekhovtsov, E. Ziemba, J. Wątróbski, and W. Sałabun, "Input data preprocessing for the mcdm model: Copras method case study," 2021.

[7] S. Opricovic and G.-H. Tzeng, "Extended vikor method in comparison with outranking methods," European journal of operational research, vol. 178, no. 2, pp. 514-529, 2007.

[8] W. Sałabun, P. Ziemba, and J. Wątróbski, "The rank reversals paradox in management decisions: The comparison of the ahp and comet methods," in International Conference on Intelligent Decision Technologies. Springer, 2016, pp. 181-191.

[9] A. Krylovas, E. K. Zavadskas, N. Kosareva, and S. Dadelo, "New kemira method for determining criteria priority and weights in solving mcdm problem," International Journal of Information Technology \& Decision Making, vol. 13, no. 06, pp. 1119-1133, 2014.

[10] D. Pamučar, Ž. Stević, and S. Sremac, "A new model for determining weight coefficients of criteria in mcdm models: Full consistency method (fucom)," Symmetry, vol. 10, no. 9, p. 393, 2018.

[11] W. Sałabun, A. Karczmarczyk, J. Watróbski, and J. Jankowski, "Handling data uncertainty in decision making with comet," in 2018 IEEE Symposium Series on Computational Intelligence (SSCI). IEEE, 2018, pp. $1478-1484$

[12] B. Kizielewicz and L. Dobryakova, "Mcda based approach to sports players' evaluation under incomplete knowledge," Procedia Computer Science, vol. 176, pp. 3524-3535, 2020.

[13] Y.-C. Chen, H.-P. Lien, and G.-H. Tzeng, "Measures and evaluation for environment watershed plans using a novel hybrid mcdm model," Expert systems with applications, vol. 37, no. 2, pp. 926-938, 2010.

[14] Y.-C. Lee, P.-H. Chung, and J. Z. Shyu, "Performance evaluation of medical device manufacturers using a hybrid fuzzy mcdm," 2017.

[15] O. Parkash and R. Kumar, "Modified fuzzy divergence measure and its applications to medical diagnosis and mcdm," Risk and Decision Analysis, vol. 6, no. 3, pp. 231-237, 2017.

[16] Ž. Stević, D. Pamučar, A. Puška, and P. Chatterjee, "Sustainable supplier selection in healthcare industries using a new mcdm method: Measurement of alternatives and ranking according to compromise solution (marcos)," Computers \& Industrial Engineering, vol. 140, p. 106231, 2020.

[17] J. Roy, K. Adhikary, S. Kar, and D. Pamucar, "A rough strength relational dematel model for analysing the key success factors of hospital service quality," Decision Making: Applications in Management and Engineering, vol. 1, no. 1, pp. 121-142, 2018.

[18] V. Y. Chen, H.-P. Lien, C.-H. Liu, J. J. Liou, G.-H. Tzeng, and L.S. Yang, "Fuzzy MCDM approach for selecting the best environmentwatershed plan," Applied soft computing, vol. 11, no. 1, pp. 265-275, 2011.

[19] A. Shekhovtsov, V. Kozlov, V. Nosov, and W. Sałabun, "Efficiency of methods for determining the relevance of criteria in sustainable transport problems: A comparative case study," Sustainability, vol. 12, no. 19, p. $7915,2020$.
[20] Ž. Stević, D. Pamučar, M. Vasiljević, G. Stojić, and S. Korica, "Novel integrated multi-criteria model for supplier selection: Case study construction company," Symmetry, vol. 9, no. 11, p. 279, 2017.

[21] M.-T. Lu, C.-C. Hsu, J. J. Liou, and H.-W. Lo, "A hybrid medm and sustainability-balanced scorecard model to establish sustainable performance evaluation for international airports," Journal of Air Transport Management, vol. 71, pp. 9-19, 2018.

[22] M. Nassereddine and H. Eskandari, "An integrated mcdm approach to evaluate public transportation systems in tehran," Transportation Research Part A: Policy and Practice, vol. 106, pp. 427-439, 2017.

[23] B. Kizielewicz, J. Więckowski, A. Shekhovtsov, J. Wątróbski, R. Depczyński, and W. Sałabun, "Study towards the time-based mcda ranking analysis-a supplier selection case study," Facta Universitatis, Series: Mechanical Engineering, 2021.

[24] S. Faizi, W. Sałabun, S. Ullah, T. Rashid, and J. Więckowski, "A new method to support decision-making in an uncertain environment based on normalized interval-valued triangular fuzzy numbers and comet technique," Symmetry, vol. 12, no. 4, p. 516, 2020.

[25] W. Sałabun, "Reduction in the number of comparisons required to create matrix of expert judgment in the comet method," Management and Production Engineering Review, vol. 5, 2014.

[26] B. Kizielewicz and J. Kołodziejczyk, "Effects of the selection of characteristic values on the accuracy of results in the comet method," Procedia Computer Science, vol. 176, pp. 3581-3590, 2020.

[27] W. Sałabun, J. Watróbski, and A. Shekhovtsov, "Are MCDA methods benchmarkable? a comparative study of TOPSIS, VIKOR, COPRAS, and PROMETHEE II methods," Symmetry, vol. 12, no. 9, p. 1549, 2020

[28] W. Sałabun and K. Urbaniak, "A new coefficient of rankings similarity in decision-making problems," in International Conference on Computational Science. Springer, 2020, pp. 632-645.

[29] W. Sałabun, A. Piegat, J. Wątróbski, A. Karczmarczyk, and J. Jankowski, "The comet method: The first mcda method completely resistant to rank reversal paradox," European Working Group Series, vol. 3.

[30] K. Palczewski and W. Sałabun, "Identification of the football teams assessment model using the comet method," Procedia Computer Science, vol. 159, pp. 2491-2501, 2019.

[31] W. Sałabun, A. Shekhovtsov, and B. Kizielewicz, "A new consistency coefficient in the multi-criteria decision analysis domain," in International Conference on Computational Science. Springer, 2021, pp. 715-727.

[32] B. Kizielewicz and Z. Szyjewski, "Handling economic perspective in multicriteria model-renewable energy resources case study," Procedia Computer Science, vol. 176, pp. 3555-3562, 2020.

[33] W. Sałabun, A. Shekhovtsov, D. Pamučar, J. Watróbski, B. Kizielewicz, J. Więckowski, D. Bozanić, K. Urbaniak, and B. Nyczaj, "A fuzzy inference system for players evaluation in multi-player sports: The football study case," Symmetry, vol. 12, no. 12, p. 2029, 2020.

[34] B. Kizielewicz and W. Sałabun, "A new approach to identifying a multicriteria decision model based on stochastic optimization techniques," Symmetry, vol. 12, no. 9, p. 1551, 2020.

[35] J. Więckowski, B. Kizielewicz, and J. Kołodziejczyk, "Finding an approximate global optimum of characteristic objects preferences by using simulated annealing," in International Conference on Intelligent Decision Technologies. Springer, 2020, pp. 365-375.

[36] - "The search of the optimal preference values of the characteristic objects by using particle swarm optimization in the uncertain environment," in International Conference on Intelligent Decision Technologies. Springer, 2020, pp. 353-363.

[37] B. Kizielewicz, A. Shekhovtsov, and W. Sałabun, "A new approach to eliminate rank reversal in the mcda problems," in International Conference on Computational Science. Springer, 2021, pp. 338-351.

[38] B. Kizielewicz and L. Dobryakova, "How to choose the optimal singletrack vehicle to move in the city? electric scooters study case," Procedia Computer Science, vol. 176, pp. 2243-2253, 2020.

[39] W. Sałabun, "The characteristic objects method: A new distance-based approach to multicriteria decision-making problems," Journal of MultiCriteria Decision Analysis, vol. 22, no. 1-2, pp. 37-50, 2015.

[40] A. Piegat and W. Sałabun, "Identification of a multicriteria decisionmaking model using the characteristic objects method," Applied Computational Intelligence and Soft Computing, vol. 2014, 2014.

[41] W. Sałabun and A. Piegat, "Comparative analysis of MCDM methods for the assessment of mortality in patients with acute coronary syndrome," Artificial Intelligence Review, vol. 48, no. 4, pp. 557-571, 2017. 